\title{
Keefektifan Konseling Kognitif dengan Strategi Reframing untuk Meningkatkan Konsep Diri Akademik Siswa SMA
}

\author{
Ujang Abdul Basir ${ }^{1}$, M. Ramli ${ }^{1}$, Adi Atmoko ${ }^{1}$ \\ ${ }^{1}$ Bimbingan dan Konseling-Universitas Negeri Malang
}

\section{INFO ARTIKEL}

\section{Riwayat Artikel:}

Diterima: 01-04-2020

Disetujui: 20-07-2020

\author{
Kata kunci: \\ cognitive group counselling, \\ reframing techniques; \\ academic self-concept; \\ konseling kelompok kognitif; \\ teknik reframing; \\ konsep diri akademik
}

\author{
Alamat Korespondensi: \\ Ujang Abdul Basir \\ Bimbingan dan Konseling \\ Universitas Negeri Malang \\ Jalan Semarang 5 Malang \\ E-mail: ujangabdbasir@gmail.com
}

\begin{abstract}
The purpose of this research is improving academic self-concept in high school students by a cognitive group counseling activities with reframing techniques modivication. The type of research used quasi experimental design that is non-equivalent control group design. The results of this study showed that there is an increase in students academic self-concepts. This is evidenced by the acquisition of Mann-Withney U between the experimental group and the control group with a value Asymp. Sig. (2-tailed) of 0,27 and this results less than 0,5 so it can be concluded that cognitive group counselling with reframing techniques is effective for improving academic self-concept in high school students. The conclusion of this research is the students academic selfconcepts in islamic high school Al-Maarif Singosari improved after given cognitive group counselling services with reframing techniques.
\end{abstract}

ABSTRAK

\begin{abstract}
Abstrak: Tujuan penelitian ini yaitu untuk meningkatkan konsep diri akademik siswa SMA melalui kegiatan konseling kelompok kognitif yang dimodifikasi dengan teknik reframing. Penelitian ini merupakan quasi experimental design dengan jenis nonequivalent control group design. Hasil dari penelitian ini menunjukkan adanya peningkatan konsep diri akademik yang dimiliki siswa SMA. Hal ini dibuktikan dengan perolehan hasil uji Mann-Whitney $U$ antara kelompok eksperimen dan kelompok kontrol yaitu dengan nilai Asymp. Sig. (2-tailed) sebesar 0,27 dan hasil ini kurang dari 0,5 sehingga dapat ditegaskan bahwasanya konseling kelompok kognitif dengan strategi reframing efektif untuk mengubah konsep diri akademik siswa SMA. Kesimpulan penelitian ini yaitu konsep diri akademik siswa SMA Al-Maarif Singosari meningkat setelah diberi layanan konseling kelompok kognitif dengan teknik reframing.
\end{abstract}

Individu yang telah memasuki pendidikan pada jenjang Sekolah Menengah Atas secara tidak langsung perkembangan individu tersebut sudah memasuki masa remaja. Lebih spesifik, Gunarsa (2006) dan Mapiare (2000) menyebutkan siswa yang sudah berada pada jenjang pendidikan SMA, secara tidak langsung telah memasuki pada masa remaja madya (pertengahan). Posisi masa remaja terletak pada masa transisi kehidupan anak dan dewasa. Dapat dikatakan fisiknya seperti orang dewasa, namun saat diperlakukan sebagaimana orang dewasa, usia remaja tidak dapat memperlihatkan sikap dewasa (Triyono et al., 2012). Pengalaman tentang alam kedewasaan minim dimiliki oleh remaja, namun biasanya masih muncul rasa gelisah, bimbang, kebingungan, dan terjadi konflik terhadap dirinya.

Sebagian besar kehidupan masa remaja dihabiskan di sekolah, tugas-tugas pokok dari seorang remaja banyak yang berkaitan dengan kegiatan sekolah. Burns (1993) mengatakan bahwa masa remaja lebih banyak penggunaan waktunya dihadapkan pada kegiatan yang ada dalam dunia pendidikan sehingga kesuksesan masa remaja dapat dilihat ketika remaja mendapatkan prestasi di sekolah atau mendapat juara dalam sebuah perlombaan/kompetisi. Bahkan jantung hati pendidikan seorang anak bagi orangtua adalah ketika mereka berhasil secara akademik atau mendapatkan juara saat mengikuti kompetisi (Triyono et al., 2012). Dengan demikian, pada usia remaja, pencapaian prestasi akademik digunakan sebagai suatu indeks harga diri paling penting bagi dirinya sendiri (Burns, 1993).

Ketika pencapaian prestasi belajar dijadikan sebagai tolok ukur harga diri bagi seorang siswa remaja, kemudian dihadapkan pula dengan perubahan fisik, perubahan emosionalitas, perubahan kognitif, dan implikasi psikososial sehingga tidak jarang pada masa ini siswa remaja memiliki kendala dalam mencapai prestasi akademik yang diharapkan oleh dirinya, orangtua maupun sekolah. Hal ini dibuktikan dengan penelitian Roderick dan Camburn tahun 1999. Mereka melacak kemajuan akademik siswa-siswi yang beralih sekolah mulai dari SD, SMP hingga SMA di Chicago. Hasil penelitiannya menemukan bahwa sebagian besar siswa menunjukkan penurunan prestasi akademik yang tajam pada tingkat sepuluh (tahun pertama SMA) (Ellis, 2008). 
Siswa remaja juga berpotensi mengalami kegagalan akademik, seperti yang diungkapkan Triyono, bahwasanya setiap tahunnya sebagian besar remaja mengalami drop out dari sekolah. Tingkat sekolah dasar kisaran $60 \%$ lanjut ke tahap menengah pertama, kisaran $40 \%$ jenjang sekolah menenah pertama yang masuk tingkat atas atau SMK, sedangkan lulusan SMA dan SMK yang masuk ke perguruan tinggi hanya $11 \%$. Selain itu, ada juga remaja yang mengulang kelas karena ketidak tercapaian kompetensi akademik pada satu level kelas (Triyono et al., 2012).

Selain itu, temuan data dalam kurun waktu 2010-2015, Institut Statistik UNESCO melalui program "Agenda Pembangunan Berkelanjutan 2030" yang berkerjasama dengan Pengawas Pendidikan Global (GEM Report) melakukan research terhadap 128 negara. Dari jumlah 260 juta anak yang tidak sekolah, ada 61 juta ditempati oleh siswa sekolah dasar (6-11 tahun). Selanjutnya, 60 juta anak ditempati oleh siswa pada jenjang sekolah menengah pertama (12-14 tahun). Kemudian tersisa, 142 juta siswa ditempati oleh siswa di jenjang menengah atas (15-17 tahun) (Utomo, 2017). Berdasarkan data pada Pusat Data dan Statistik Pendidikan dan Kebudayaan Indonesia angka putus sekolah dan mengulang pada tingkat SMA yang berada pada tahun ajaran 2016/2017 setidaknya terdapat 36.419 siswa kelas X, 12.551 siswa XI, 11. 743 siswa, dan siswa XII ada 12. 125. Selain itu, 7. 340 siswa mengulang belajar dengan rincian kelas X 3.889 siswa, kelas XI 2.727 siswa, dan kelas XII 724 siswa (Kemendikbud, 2017). Dari data tersebut, dapat kita lihat bahwa ketika dihadapkan pada sesuatu keadaan perubahan emosi, kognisi, dan kecemasan maka proses belajar siswa remaja akan mengalami hambatan yang berarti bagi dirinya. Dalam temuan peneliti di lapangan, dari rentang waktu bulan Agustus-November 2019 ada sekitar 50 siswa SMA Islam Al-Maarif Singosari yang terindikasi rajin melanggar tata tertib sekolah yang katagorikan pada "siswa perlu penanganan khusus". Bentuk pelanggaran yang sering dilakukan seperti, tidak hadir tanpa keterangan, terlambat masuk sekolah, meninggalkan pelajaran tanpa alasan, menggunakan alat komunikasi (HP) saat pelajaran, dan pulang sebelum waktunya. Dari ke 50 siswa tersebut didominasi oleh siswa kelas X dengan jumlah 20 siswa, kelas XI 16 siswa, dan kelas XII 14 siswa. Selain itu, sudah ada lima siswa yang memutuskan tidak melanjutkan sekolah.

Kegagalan belajar yang dialami oleh siswa remaja bukan semata-mata disebabkan karena faktor sosial ekonomi, melainkan ada faktor lain dari dalam dirinya yang memicu terjadi kegagalan seperti itu. Temuan data Riyadiningsih menggambarkan anak drop out sekolah yang ada di desa dan kota dengan jumlah yang tidak jauh beda diantara keduanya. Data itu menggambarkan bahwa faktor primer terjadinya drop out sekolah pada anak, tidak semata-mata permasalahan keadaan wilayah dan kehidupan sosial ekonomi. Secara implisit, dari hasil penelitian itu menunjukkan bahwa ada faktor lain yang memicu kendala itu terjadi. Faktor itu berasal dari diri (kondisi psikologis) remaja itu sendiri yang memengaruhi siswa remaja mengambil keputusan berhenti sekolah (Riyadiningsih \& Astuti, 2018). Didukung juga oleh Saifullah, bahwa salah satu faktor yang menyebabkan terjadinya kegagalan mencapai prestasi akademik disebabkan oleh faktor internal yang berhubungan dengan faktor psikologis individu itu sendiri seperti halnya konsep diri, motivasi, dan efikasi diri (Saifullah, 2015). Namun, Guay menjelaskan ternyata self-concept academic/konsep diri akademiklah yang menjadi ukuran prestasi akademik yang akan didapatkan oleh siswa (Guay et al., 2010). Demikian juga dengan Zahra yang mengungkapkan ada korelasi antara konsep diri akademik yang dimiliki dengan capaian hasil belajar yang siswa akan peroleh. (Zahra et al., 2010). Jadi, dapat disimpulkan bahwa konsep diri akademik lebih berperan besar terhadap prestasi siswa yang akan diraih. Semakin tinggi konsep diri akademik yang dimiliki siswa semakin rendah juga kegagalan akademik yang akan ditemuinya.

Konsep diri akademik itu sendiri adalah sekumpulan penilaian siswa/peserta didik terhadap kemampuan diri yang berkaitan dengan bidang akademik/belajar yang didalamnya terdiri dari persepsi dan perasaan siswa terhadap kompetensi akademik, serta komitmen dan minat terhadap tugas akademik. Sebagaimana yang dinyatakan oleh Guay (Guay et al., 2010) bahwa konsep diri akademik adalah cara pandang siswa terhadap diri pribadinya yang dihasilkan dari historis belajar dan tafsiran mengenai dirinya saat berada di lingkungan belajarnya. Peneliti lain seperti Shevelson dan Bolus, menafsirkan konsep diri akademik itu bagian dari bentuk penilaian siswa terhadap kompetensi akademik yang selama ini dimilikinya yang terdiri dari persepsi dan perasaan yang ada saat menerima dirinya saat belajar, keyakinan, dan martabat dirinya (Shavelson \& Bolus, 1982). Sedangkan Liu, Wang, dan Parkins, menjelaskan konsep diri akademik adalah suatu kepercayaan diri dalam belajar dan ikhtiar yang dilakukan untuk mengerjakan segala bentuk tugas yang diberikan guna mendapatkan prestasi belajar yang diharapkan (Liu \& Wang, 2005).

Upaya yang dapat dilakukan untuk perubahan terhadap konsep diri akademik siswa dapat menggunakan konseling kognitif dengan teknik reframing. Hal ini dikarenakan konsep diri akademik terbentuk melalui proses berpikir individu. Konseling kognitif dengan teknik reframing cocok untuk meningkatkan konsep diri akademik karena konseling kognitif itu sendiri digunakan untuk mengubah keyakinan irrasional, persepsi kurang tepat, dan ungkapan negatif yang melatarbelakangi perilaku maladaptive individu (Stuart \& Laraia, 2005). Selain itu, metode perilaku kognitif diasumsikan dapat memengaruhi tingkah laku individu melalui penerapan teknik kognitif dan perilaku (Ramli, 2005). Salah satu teknik dari konseling kognitif adalah reframing (Rosalia. 2015). Wiwoho memberi pengertian terhadap teknik reframing (2011) yaitu suatu upaya untuk melabeli kembali suatu peristiwa, dengan cara mengganti pandangan dari sudut yang lain tanpa mengubah kejadiannya. Sementara itu, menurut Cormier dkk, (2009) reframing disebut juga sebagai pelabelan ulang yang mempunyai makna sebagai suatu teknik untuk menata ulang cara pandang individu terhadap suatu peristiwa atau perilaku. 
Adapun Watzlawick (dalam (Mattila, 2001) teknik reframing adalah suatu cara yang dipakai untuk menyusun suatu persepsi emosi atau pandangan yang berhubungan dengan kejadian, kemudian ditempatkan pada pola pandang baru yang lebih baik dari sebelumnya. Jadi, perubahan persepsi melalui konseling kognitif dengan teknik reframing merupakan proses restukturisasi kognitif dengan cara membingkai ulang persepsi awal konseli dan menempatkannya dibingkai lain yang lebih baik dari sebelumnya. Tujuan dari teknik reframing adalah untuk mereorganisir konten emosi yang dapat merendahkan konsep diri akademik siswa dan memberikan frame lagi ke pola pandang yang fungsional yang dapat meningkatkan konsep diri akademik siswa.

Berdasarkan latar belakang yang ada, maka peneliti akan menggunakan teknik reframing sebagai cara mengubah konsep diri akademik siswa SMA Islam Al-Maarif Singosari. Dari hasil temuan data diharapkan memberi sumbangsih keilmuan untuk peneliti lainnya agar dapat mengembangkan eksperimen lanjutan tentang konseling kelompok kognitif dengan teknik reframing untuk mengubah konsep diri akademik siswa SMA.

\section{METODE}

Desain eksperimen yang dipakai pada penelitian ini merupakan jenis non equivalent pretest - posttest control group design. Kemudian untuk subjek penelitian ini yaitu siswa kelas X SMA Islam Al-Maarif Singosari pada tahun ajaran 2019/2020. Jumlah subjek terdiri dari 10 siswa yang dipilih melalui inventori konsep diri akademik yang sudah dikembangkan oleh peneliti. Inventori konsep diri akademik awalnya terdiri dari 40 butir setelah dilakukan validitas konstruk dengan analisis faktor eksploratori component principal dihasilkan 15 butir yang valid untuk mengukur konsep diri akademik siswa SMA Islam AlMaarif Singosari. Tujuan pengujian kontruk dengan analisis faktor eksploratori yaitu untuk meninjau butir valid dan menghilangkan butir tidak valid dengan kriteria valid $\geq 0,5$ terhadap aspek yang dibangun (Hair, dalam Adi Atmoko, 2012). Dari 10 subjek, selanjutnya dibuat menjadi dua kelompok yaitu kelompok eksperimen dan kelompok pembanding. Untuk kelompok eksperimen, peneliti menggunakan intervensi konseling kognitif dengan teknik reframing untuk meningkatkan konsep diri akademik siswa, kemudian untuk kelompok kontrol menggunakan teknik diskusi yang dimodifikasi dengan focus group discussion.

\section{HASIL}

Hasil dari analisis statistik terhadap data pretest dan posttest menunjukkan, bahwa semua subjek penelitian baik itu kelompok eksperimen atau kelompok kontrol mengalami peningkatan terhadap konsep diri akademik. Namun, peningkatan tersebut yang lebih signifikan perubahannya terdapat pada subjek yang termasuk pada kelompok eksperimen yang diberikan konseling kelompok kognitif dengan strategi reframing daripada subjek yang termasuk pada kelompok kontrol yang diintervensi dengan teknik focus group discussion. Hasil statistik yang didapatkan dari uji Mann-Whitney $U$ terhadap dua kelompok penelitian yaitu Asymp. Sig. (2-tailed) 0,27, dan hasil ini kurang dari 0,5 sehingga dapat disimpulkan bahwa konseling kelompok kognitif dengan teknik reframing efektif untuk meningkatkan konsep diri akademik siswa SMA Islam Al-Maarif Singosari.

\section{PEMBAHASAN}

Hasil temuan data penelitian di lapangan menunjukkan bahwa konseling kelompok kognitif dengan teknik reframing terbukti efektif untuk meningkatkan konsep diri akademik siswa SMA Islam Almaarif Singosari. Siswa yang memasuki perkembangan masa remaja rentang memiliki konsep diri akademik rendah sehingga membuat proses belajarnya menjadi terganggu. Menurut peneliti, rendahnya konsep diri akademik siswa SMA disebabkan karena keadaan perubahan emosi, kognisi dan kecemasan yang dialami pada masa remaja serta respons yang diberikan terhadap problem yang dihadapi dipersepsikan dengan proses berpikir yang kurang tepat. Dengan demikian, pada saat mengalami keadaan yang tidak diharapkan cenderung menjauhi keadaan tersebut. Hal ini ditemukan oleh peneliti di lapangan, terutama kelas X SMA Islam Al-Maarif Singosari masih rentan terkena permasalahan belajar seperti, bolos sekolah, tidak mengerjakan PR, keluar pada saat pelajaran berlangsung, lebih mementingkan aktivitas lain daripada sekolah, dan masuk sekolah pada mata pelajaran atau hari tertentu saja bahkan yang lebih parah ada siswa yang ingin berhenti sekolah. Permasalahan belajar siswa diakibatkan dengan adanya konsep diri akademik yang rendah sehingga keyakinan terhadap kemampuan akademik dan usaha yang dilakukan menjadi kurang maksimal. Permasalahan belajar siswa tersebut harus ditangani dengan teknik yang tepat dan cocok serta dapat meningkatkan konsep diri akademik siswa semakin meningkat.

Ciri dari konsep diri akademik tinggi ditandai dengan memiliki kemampuan berkomunikasi secara positif dengan gurunya, serta ikut terlibat dalam kegiatan proses akademiknya. Sebagaimana yang dijelaskan Rauh dalam hasil penelitiannya (2013) bahwa konsep diri akademik tinggi mempunyai karakteristik seperti (1) mempunyai kepercayaan dan kemampuan dalam menyelesaikani suatu hambatan, (2) mempunyai kesadaran bahwasanya lingkungan tidak selamanya mendukung setiap rasa, keinginan atau perilakunya, (3) dapat mengubah diri menjadi lebih baik, (4) mempunyai keyakinan diri dan (5) mempunyai model menerima penghormatan tanpa rasa malu. Jadi, secara keseluruhan siswa yang memiliki konsep diri akademik tinggi akan cenderung memiliki keyakinan diri untuk melaksanakan semua kegiatan akademiknya. Siegle (McCoach \& Siegle, 2003) juga 
ikut menggambarkan tentang bagaimana konsep diri akademik tinggi, tetapi cakupannya lebih luas tidak hanya terbatas dalam proses kegiatan akademik siswa, melainkan konsep diri akademik positif memiliki berkorelasi terhadap perilaku akademik siswa diluar kegiatan pembelajaran. Seperti mengulang kembali pelajaran di rumah, mengerjakan tugas-tugas sekolah di rumah, dan membaca pada waktu luang.

Penerapan strategi konseling kognitif menggunakan reframing untuk mengubah konsep diri akademik siswa SMA Islam Al-Maarif Singosari cocok untuk dilakukan, karena keberhasilan belajar siswa salah satunya disebabkan oleh konsep diri (Saifullah, 2015). Konsep diri akademik itu sendiri terbentuk melalui proses berpikir individu sehingga jika terjadi konsep diri akademik rendah maka strategi yang digunakan untuk meningkatkan konsep diri akademik harus dengan teknik yang fokus pada proses berpikir individu, salah satu teknik yang dapat digunakan yaitu konseling kelompok dengan teknik reframing. Hal ini juga diperkuat dengan hasil penelitian Gerber, Reiff, \& Ginsberg, mereka melakukan kajian penelitian kepada siswa yang memiliki kesulitan belajar, dimanan siswa merasa tidak mampu untuk menerima beban pelajaran dari gurunya (Gerber et al., 1996). Setelah diberikan teknik reframing, pada tahun pertama siswa dapat meraih kesuksesan belajarnya. Hal tersebut disebabkan siswa memiliki kesadaran dan pemahaman baru mengenai kemampuan diri, situasi, dan juga pemahaman akan apa yang menjadi kekuatan dan kelemahan diri serta efeknya pada proses belajar.

Selain itu, penggunaan teknik reframing untuk meningkatkan belajar siswa sudah banyak dilakukan di Indonesia dan hasilnya efektif. Seperti reframing efektif untuk meningkatkan motivasi siswa dalam mengikuti pelajaran (Utamaya et al., 2013). Kemudian, reframing efektif unuk mengurasi rasa takut siswa terhadap guru (Rahmatika et al., 2013). Reframing efektif untuk meminimalisir Learned Helplessness siswa SMA (Laksmi et al., 2014). Selanjutnya, reframing efektif untuk meningkatkan kesadaran diri siswa dalam belajar siswa (Mudana, et al., 2014). Walaupun penelitian yang dilakukan tidak langsung kepada aspek konsep diri akademik, namun secara tidak langsung aspek yang dirubah atau ditingkatkan oleh teknik reframing ada korelasinya dengan konsep diri akademik.

Keberhasilan penerapan strategi konseling kelompok kognitif dengan teknik reframing didukung juga dengan prosedur yang jelas sehingga memudahkan peneliti untuk melakukannya. Diantara prosedur teknik reframing yaitu (1) rasional strategi reframing dan fokus masalah yang ingin disembuhkan, (2) menemukan cara pandang dan perasaan konseli pada saat peristiwa yang tidak nyaman, (3) meninjau ulang pandangan yang memicu timbulnya permasalahan, (4) mengumpulkan alternatif persepsi (5) mengolaborasikan persepsi terpilih pada situasi yang dinilai suatu permasalahan, dan (6) memberikan tugas rumah dan tindak lanjut (Cormier dalam Nursalim, 2013). Dengan adanya prosedur yang jelas dapat membantu juga peneliti agar mencapai tujuan yang dikehendaki.

Berdeda dengan strategi pembanding yang dipakai oleh peneliti yaitu teknik diskusi yang dimodifikasi dengan focus group discussion, walaupun terbukti efektif dalam konsep diri akademik siswa SMA Islam Al-Maarif Singosari, tetapi perubahannya itu lebih sedikit jika dibandingkan dengan teknik reframing. Data menunjukkan hasil uji Mann-Whitney $U$, untuk kelompok eksperimen mendapatkan nilai (Asymp. Sig. (2-tailed),043) sedangkan kelompok control (Asymp. Sig. (2-tailed),042). Dari data tersebut, dapat disimpulkan bahwa perubahan kelompok eksperimen yang diintervensi dengan konseling kelompok kognitif dengan teknik reframing perubahannya lebih besar daripada kelompok kontrol yang diintervensi dengan teknik diskusi yang dimodifikasi dengan focus group discussion. Berdasarkan data tersebut, kita dapat menentukan bahwa konseling kelompok kognitif dengan teknik reframing lebih efektif untuk meningkatkan konsep diri akademik siswa SMA Islam Al-Maarif Singosari.

\section{SIMPULAN}

Merujuk pada uraian dan kajian terhadap temuan data penelitian, maka bisa dikatakan bahwa konseling kognitif menggunakan strategi reframing terbukti ampuh dalam mengubah konsep diri akademik siswa. Konselor dapat menggunakan hasil penelitian ini untuk dijadikan acuan pada saat memberikan konseling kepada siswa yang mempunyai konsep diri akademik rendah. Kepada peneliti lain dapat mengembangkan penelitian dengan jumlah subjek skala besar agar hasil dari penelitian dapat digeneralisasikan.

\section{DAFTAR RUJUKAN}

Agustina, I., \& Lukitaningsih, R. (2014). Penerapan Strategi Reframing untuk Mengurangi Perasaan Rendah Diri Siswa Kelas VII-H SMP Negeri 1 Jogorogo Ngawi. Jurnal BK UNESA, 4(3), 710-717.

Atmoko. A. (2012). Bahan Ajar Matakuliah Desain dan Analisis Data. Malang. Universitas Negeri Malang

Bayu, M. V. S., \& Pratiwi, T. I. (2016). Penerapan Strategi Reframing untuk Meningkatkan Kemampuan Berpikir Positif Siswa Kelas X APK-2 SMKN 1 Surabaya. Jurnal BK UNESA, 6(1), 1-7.

Burns, R. B. (1993). Konsep Diri, Teori, Pengukuran, dan Perilaku. Jakarta: Penerbit Arcan.

Burns. D. (1990). Terapi Kognitif: Pendekatan Baru bagi Penanganan Depresi. Alih Bahasa Santosa. Jakarta: Erlangga.

Cormier, S., Nurius, P., \& Osborn, C. J. (2009). Interviewing and Change Strategies for Helpers: Fundamental Skills and Cognitive Behavior Interventions. USA: Brooks/Cole. Google Books. 
Gerber, P. J. Reiff, H. B, \& Ginsberg, R. (1996). Reframing The Learning Disabilities Experience. Journal Learning Disabilities, 29(1), 98-101.

Guay, T., Ratelle, F., Roy, C.F., Litalien, A., David. (2010). Academic Self-Concept, Autonomous Academic Motivation, and Academic Achievement: Mediating and Additive Effects. Journal of Faculty of Educational Sciences, Laval Universit. 20, 644-653.

Gunarsa, S. D., \& Gunarsa, Y. S. D. (2006). Psikologi Perkembangan Anak dan Remaja. Jakarta: PT BPK Gunung Mulia.

Laksmi, K. L., Antari, N. N. M., Dantes, N. (2014). Penerapan Konseling Rasional Emotif dengan Teknik Reframing untuk Meminimalisir Learned Helplessness pada Siswa Kelas XI IPA 3 SMA Negeri 3 Singaraja Tahun Ajaran 2013/2014. Jurnal Online Jurusan Bimbingan Konseling, 2, 1

Liu, W. C., \& Wang, C. K. J. (2005). Academic Self-Concept: A Cross-Sectional Study of Grade and Gender Differences in A Singapore Secondary School. Asia Pacific Education Review, 6, 1.

Mapiare, A. (2000). Psikologi Remaja. Surabaya: Usaha Nasional.

Mattila, A. (2001). Seeing Things in A New Light: Reframing in Therapeutic Conversation. Helsinky: Helsinky University Press.

Mudana, I. N. O., Dharsana, I. K., Suranata, K. (2014). Penerapan Konseling Gestalt dengan Teknik Reframing untuk Meningkatkan Kesadaran Diri Dalam Belajar Siswa Kelas VIII A1 SMP Negeri 4 Singaraja Tahun Ajaran 2013/2014.e-journal Undiksa Jurusan Bimbingan Konseling, 2(1)

Nursalim. (2014). Strategi dan Intervensi Konseling. Jakarta: PT Indeks.

Rahmatika, R., Warsito, H., Farminto, E., Lukitaningsih, R. (2013). Keefektifan Strategi Reframing untuk Membantu Siswa Mengurangi Rasa Takut terhadap Guru Bimbingan Konseling. Jurnal BK UNESA, 1(3) 301-307.

Ramli, M. 2005. “Terapi Perilaku Kognitif”. Artikel. Dalam Mamat Supriatna (2005). Pendidikan dan Konseling di Era Global. Bandung: BK UPI

Rauh, I. Y. (2013). Kontribusi Kompetensi Profesional Guru, Konsep Diri Akademik Serta Motivasi Kerja Guru terhadap Kinerja Guru Matematika di Tingkat SMA Se-Kabupaten Karangasem. Jurnal Penelitian Pascasarjana Undiksha, (4), $1-14$.

Riadiningsih, H. \& Astutik, R. P. (2018). Kondisi Psikologis Anak Putus Sekolah. Proceeding Seminar Nasional \& Call for Papers (SCA-3), 3(1).

Rosalia. D. N. (2015). Perbedaan Komitmen Tugas Siswa SMP Negeri 4 Malang Melalui Penerapan Teknik Reframing dan Self Instruction. Tesis tidak diterbitkan. Universitas Negeri Malang, Malang.

Saifullah. 2015. Hubungan Konsep Diri Akademik dengan Prestasi Akademik. Jurnal Lisan Al-Hal Fakultas Dakwah IAI Ibrahimi, 7(2), 449-458.

Siegle, D., McCoach, B. (2003). The Structure and Function of Academic Self-Concept in Gifted and General Education Students. Roeper Review, 25(2), 61-65.

Triyono., Hidayah, N., Zen, E.F., Bisri, M., Flurentin, E., Hotifah, Y., Farida, I. A. (2012). Perkembangan Peserta Didik. Malang. FIP UM.

Utamaya, E. L., Pratiwi, T. I., Nursalim, M., Setiawati, D. (2013). Penerapan Konseling Kelompok dengan Strategi Reframing untuk Meningkatkan Motivasi Siswa Mengikuti Pelajaran di Kelas di SMP Negeri 1 Kandat. Jurnal BK UNESA, 1(3), $224-230$.

Wiwoho. R. (2004). Kunci Hidup Bahagia 24 Jam Sehari. Jakarta: Gramedia Pustaka Utama.

Zahra, T. A. 2010. Relationship of Academic, Physical and Social Self-Concepts of Students with Their Academic Achievement. $3(3), 73-78$. 